\title{
Genetic control of epidermis differentiation in Drosophila
}

\author{
FRANÇOIS PAYRE* \\ Centre de Biologie du Développement, Université Paul Sabatier, Toulouse, France
}

\begin{abstract}
In arthropods, the animal body is isolated from the external environment by a protective exoskeleton called the cuticle. The cuticle of young larvae has certainly been the most scrutinized structure in Drosophila and genetic studies of the pattern of cuticular extensions has provided the main source of our comprehension of the control of embryonic development. However, the complex structure of the cuticle remains poorly understood and analysis of the underlying epidermis has started only recently. Here I review different aspects of epidermis differentiation with the aim of presenting an integrated view of the organisation of the Drosophila integument. Although profound differences in epidermis organisation are observed across species, accumulated results suggest that epidermis formation and differentiation might share an unsuspected number of homologies between Drosophila and vertebrates.
\end{abstract}

KEY WORDS: Drosophila, integument, cuticle, epidermis, morphogenesis, cell polarity

\section{Introduction}

When compared with the sophisticated organogenesis of amniote skin, which involves numerous cellular interactions between two distinct tissues of different developmental origin (dermis and epidermis), with each being composed of several cell layers (or stratum), the formation of the Drosophilaintegument appears as a far simpler process. The insect integument is made of a monolayer of epidermal (or hypodermal) cells and most of the signalling pathways that are responsible for epidermis morphogenesis therefore take place in a two dimensional space. In addition, the protective properties of the integument in respective phyla are achieved through different strategies. While the intracellular cytoskeleton of intermediate filaments (keratins), together with associated proteins in superficial layers, plays a critical role of protection in vertebrates, the insect epidermis is shielded by a complex extracellular structure, referred to as the cuticle. Thanks to the stereotyped pattern of cuticular extensions that decorate the external surface of Drosophila larvae, several generations of geneticists have been able to identify determinants of the fly development, leading to the discovery of many genetic networks governing embryonic segmentation. Unfortunately, earlier efforts made to understand how the complex larval cuticle is formed have not been extensively pursued through genetic analysis. On the other hand, Drosophila embryonic epidermis has became a powerful model system to identify functional determinants of epithelial cell polarity and morphogenesis. Finally, studies on the evolution of larval extension patterns have provided novel insights into our understanding of the molecular mechanisms involved in morphological diversification. However, it is worth remembering that all these processes are taking place in the same cells and must be integrated during developmental. The aim of this review is to summarise what we have learned from the analysis of various aspects of Drosophilaepidermal cell differentiation (each reviewed in details elsewhere) in an integrated view along the embryonic development. I shall focus, in a roughly chronological order, on the genetic control of the critical steps of epidermis formation and differentiation. These include establishment of the epithelium, acquisition of polarity cues, generating identity diversity in cell field, control of cell shape and finally deposition of highly ordered cuticle layers.

\section{Histogenesis of the Drosophila epidermis}

Unlike many other systems, the Drosophilaepidermis is formed without passing through mesenchymal intermediates and is thus referred to as a primary epithelium (Muller, 2000). Early Drosophila development begins with rapid nuclear divisions, which take place without cytokinesis and give rise to a multinucleated syncytial embryo. At the end of the thirteen division, when approximately 5000 nuclei have reached the syncytial cortex, the epithelium is formed by a peculiar process called cellularization. Each nucleus

Abbreviations used in this paper: DER, Drosophila EGF receptor; Hh, Hedgehog; PDZ, a protein motif originally found in PDS95/DLG/ZO1 proteins; SAR, subapical region; svb, the shavenbaby gene; $\mathrm{Wg}$, Wingless.

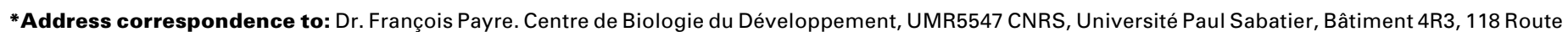
de Narbonne, 31062 Cedex 4, Toulouse, France. e-mail: payre@cict.fr
} 
becomes separated from its neighbours by the plasma membrane which invaginates between adjacent nuclei (Loncar and Singer, 1995), generating the first embryonic cell layer. Cellularization requires rapid (1h) and huge (more than 20 fold) membrane growth, which is achieved through insertion of intracellular vesicles at specific sites in the growing membrane (Lecuit and Wieschaus, 2000). In addition to proteins synthesised from maternal mRNAs (Sullivan etal., 1993), cellularization was shown to require the activity of several embryonic genes (Wieschaus and Sweeton, 1988). These zygotic genes are involved in polarised membrane growth (nullo (Simpson and Wieschaus, 1990) and slam (Beronja and Tepass, 2002; Lecuit et al., 2002)) and also in actin organisation (sry- $\alpha$ (Schweisguth et al., 1990), bottleneck (Schejter and Wieschaus, 1993) scr64B and tec29(Thomas and Wieschaus, 2004)). A highly dynamic actin reorganisation takes place during cellularization (Warn et al., 1980; Warn and RobertNicoud, 1990; Young et al., 1991) and understanding its interaction with localised membrane growth will require further work. After completion of cellularization, the blastoderm embryo is composed of a monolayer of cells that display an epithelial organisation.

After formation of the blastoderm, two further rounds of mitosis (Foe, 1989) provide an appropriate number of epidermal cells, which is finely tuned by a limited amount of apoptosis (Pazdera et al., 1998). Fate mapping has shown that epidermis derive from the lateral parts of the blastoderm epithelium (Fig. 1). To enclose embryonic tissues, the epidermis has thus to fill a dorsal gap (let by the retraction of the germ band), in a morphogenetic movement called dorsal closure (see (Jacinto et al., 2002b) for a recent review). Without cell division, lateral epidermal cells stretch along the dorsal-ventral axis to eventually cover the aminoserosa dorsally (a transient extra-embryonic membrane). Epidermal cells from the left and right sides ultimately fuse in the dorsal-most

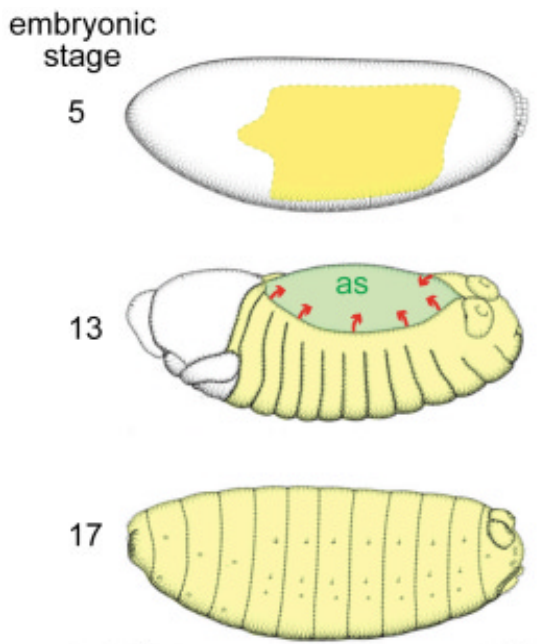

anterior

posterior

Fig. 1. Epidermal cells of the Drosophila embryo: origin and formation of the tissue. Drosophila epidermal cells derive from the main part of the lateral epithelium (yellow) in blastoderm embryos (stage 5). At stage 13, the left and right sides of the epidermis elongate dorsally to enclose the amioserosa (as), a transient extraembryonic membrane. After the completion of dorsal closure, the epidermis forms the external surface of late embryos (stage 17) and actively synthesizes the cuticle envelope. region, via a purse-string-like process (Jacinto et al., 2002a) that involves reorganising the acto-myosin cytoskeleton (Young etal., 1993; Jacinto et al., 2000; Kiehart et al., 2000). Failure of this process leads to embryos presenting a hole in the dorsal cuticle, a phenotype that has allowed the genetic identification of numerous players (reviewed in (Noselli and Agnes, 1999)). Dorsal closure is orchestrated by signalling pathways (Knust, 1997), such as Decapentaplegic (Dpp a TGF- $\beta$ homologue) that initiates the process and the JNK pathway (Glise et al., 1995), a key Dpp regulator (Glise and Noselli, 1997) that activates the expression of target genes through the Fos/Jun (AP-1) transcriptional adaptator complex (Hou et al., 1997). Dorsal closure present functional similarities with vertebrates wound healing (Wood et al., 2002) and further genetic analysis will certainly help understanding both these fundamental processes.

\section{Establishment of apical-basal polarity}

A critical feature of the Drosophilaepidermis is the formation of cell junctions that ensure tissue organisation and function. In addition, epidermal cells are highly polarised along the apicalbasal axis, with the apical region corresponding to the external surface of the embryo. Recent analyses have shown that these two aspects of epidermis organisation are interdependent and more connected than previously assumed (Lecuit and Wieschaus, 2002).

The first signs of junction establishment are already observable during cellularization and define different membrane domains along the baso-apical axis. These early polarisation cues are rapidly reinforced through the activity of embryonic genes. A key step is the formation, from the earlier dispersed spot junctions, of a continuous ring of apical adherens junctions connected with actin filaments, the zonula adherens. Zonula adherens contribute to epithelium cohesion and prevent diffusion of molecules along lateral membranes and between adjacent cells (Knust and Bossinger, 2002). Inactivation of shotgun (Tepass, 1996) or armadillo (Muller and Wieschaus, 1996), which encode major components of adherens junctions (DE-cadherin and $\beta$ catenin, respectively), results in the loss of epithelial features. In addition, adherens junctions are a major element of epithelial polarity and, together with other protein complexes, define successive basal-apical regions (Fig. 2). Schematically, the apicalmost membrane domain can be characterised by the localisation of a membrane protein, Stranded-at-second (Sas) (Schonbaum et al., 1992) and the secretion of Yellow (Kornezos and Chia, 1992), a protein putatively involved in catecholamine synthesis (see below). The apical domain is specified by a protein complex that is composed of two PDZ proteins, Bazooka (Par3) (Benton and St Johnston, 2003) and DmPar6 (Hurd et al., 2003) and the Drosophila atypical protein kinase (DaPKC) (Rolls et al., 2003). A subapical region (SAR or Marginal Zone) lies between the apical cell face and the adherens junctions and is determined by a second protein complex. The SAR domain is organised by Crumbs, a transmembrane protein thought to participate in tissue cohesion through homotypic extracellular interactions (Tepass et al., 1990). Consistent with this interpretation, embryos mutant for crumbs (like those lacking bazooka) display a dramatic phenotype, with the absence of most of the cuticle resulting from a highly disorganised epidermis (Tepass etal., 1990). A short cytoplasmic 
tail also appears critical for Crumbs function in the embryonic epidermis as it recruits Stardust, a Membrane Associated GUanylate Kinase (MAGUK) and two actin binding proteins: $\beta$ Spectrin and Dmoesin (Medina et al., 2002; Polesello and Payre, 2004). How these two latter proteins, together with $\alpha$-Catenin, anchor actin microfilaments to cell junctions remains to be elucidated. Basal to adherens junctions, the membrane-associated proteins FasIll (Woods et al., 1997), Coracle (Lamb et al., 1998) and Neurexin (Baumgartner et al., 1996) are involved in the establishment of septate junctions. Two other proteins, Scribble and Disc-large (Dlg), which localise laterally, are also required for the correct establishment of adherens junctions and cell polarity. Scribble and DIg contain PDZ motifs associated with leucine rich regions or $\mathrm{SH} 3$ and GUK domains, respectively (Bilder et al., 2003). Interestingly, in embryos mutants for scribble, the localisation of apical proteins extends basally, a phenotype reminiscent of crumbs overexpression (Bilder et al., 2003). This indicates that the different membrane domains are dynamic structures, whose formation and/or maintenance is interdependent. Finally, the basal face of Drosophila epidermal cells also displays the localised accumulation of specific proteins, such as integrins that mediate interaction with the basal membrane. The respective role of the numerous players identified by genetic analysis will require further work to be fully understood. Nevertheless, available data already indicate that a tight link exists between epithelial junctions and polarity and that, although spatially separated, the differently protein complexes functionally interact. Concomitantly with the establishment their apical-basal polarity, epidermal cells are also specified into different cell fates along both the antero-posterior and dorso-ventral axis.

\section{General principles of Drosophila segmentation}

One of the most prominent features of the Drosophila cuticle is its metameric organisation, with a stereotyped array of nonsensory extensions (microtrichiae, generally referred to as trichomes) that underline the segmented nature of the body (Fig. $3 A)$. The dorsal region is almost completely covered by thin trichomes (or dorsal hairs). The ventral side presents belts of larger pigmented extensions, the denticles, which are involved in larval locomotion. Following a segmental pattern that includes differences between thorax and abdomen, denticles belts alternate with smooth, or naked, regions (see (Martinez Arias, 1993) for review)

It was a formidable break-through, when Christiane NussleinVolhard and Eric Wieshaus realised that looking at the cuticles of a large collection of mutants (Nusslein-Volhard and Wieschaus, 1980) could be an efficient means of identifing genes controlling embryonic development (Nusslein-Volhard etal., 1984). Bringing together genetics and embryology, their work paved the way for the discovery of most of the fundamental mechanisms of embryonic development (Cohen, 1995). The cascade of genetic regulations responsible for the establishment of Drosophila segmentation is nowadays an inescapable chapter of textbooks and will be only briefly mentioned here. The general principle is a progressive restriction of the expression domains of genes encoding transcription regulators (see (St Johnston and Nusslein-Volhard, 1992; Pankratz and Jäckle, 1993) for review). The definition of body axes starts prior fertilisation, during oogenesis, when cellu-

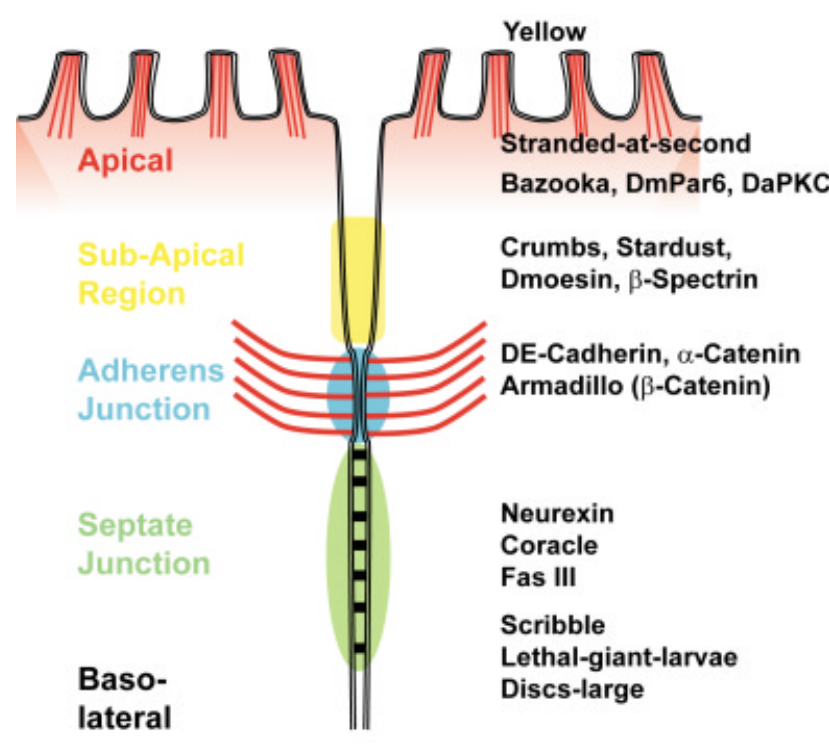

Fig. 2. Organisation of polarised epidermal cells and junctional complexes. The embryonic epidermis is composed of a monolayer of cells which are highly polarised along the apical (top) basal axis. Successive membrane domains are defined by the localised distribution of numerous membrane-associated (Crumbs, DE-Cadherin, Neurexin), scaffolding (Stardust, Armadillo, Coracle, Discs-large) and actin-binding (Dmoesin, $\beta$ Spectrin, $\alpha$-catenin) proteins. The apical-most region of epidermal cells differentiates actin (red lines) rich microvilli. Two distinct junctional complexes (adherens and septate junctions) regulate cell-cell adhesion.

lar transports lead to asymmetrical localisation of maternal determinants within the oocyte. From these localised sources, simple diffusion accounts for the formation of morphogen gradients (St Johnston and Nusslein-Volhard, 1992) that are eventually interpreted by embryonic nuclei to set up the expression of primary embryonic segmentation genes, or gap genes, in large domains. These domains are then progressively subdivided in narrower stripes, through the activity of the so-called pair-rule and segment polarity genes. This leads, at the blastoderm stage, to 14-15 contiguous regions that correspond to future segments (St Johnston and Nusslein-Volhard, 1992; Pankratz and Jäckle, 1993). In each of these regions, Wingless (Wg, a founding member of the Wnt family of extracellular signalling molecules (Wodarz and Nusse, 1998)) and Hedgehog (Hh, a cholesterol modified signalling protein, see (Ingham and McMahon, 2001) for a recent review) are expressed in two adjacent stripes of cells, on each side of a transient morphological groove, the parasegmental (PS) boundary (see Martinez Arias, 1993). This PS frontier separates two groups of cells along the AP axis, the anterior and posterior compartments. Each segment corresponds to the juxtaposition of an anterior and a posterior compartment (Martinez Arias, 1993), that will be highlighted by the segmental grooves (Larsen et al., 2003), first observable at mid-embryogenesis and that persist through the larval periods. In early stages of embryogenesis, Wgand hhexpressions are interdependent: reception of the $\mathrm{Wg}$ signal in posterior cells activates the expression of the transcription factor Engrailed, which triggers the expression of $h h$ (Martinez Arias, 1993). Through diffusing to anterior cells, the secreted factor Hh acts in turn to maintain wgexpression (Ingham, 
1993). This early positive feedback loop that reinforces the PS boundary is not maintained at later stages (see (Sanson, 2001), when $\mathrm{Wg}$ and $\mathrm{Hh}$ act subsequently to specify cellular identity within compartments.

\section{Generating intra-segmental epidermal cell diversity}

Following their role in segmentation, the $\mathrm{Wg}$ and $\mathrm{Hh}$ pathways become involved in the determination of epidermal cell fate, which is characterised by corresponding cuticular organisation. Dorsally, in each thoracic segment, four different kinds of cuticular structures are formed and referred to as type 1 to 4 (Fig. 3B). Type 1 corresponds to a single row of large pigmented trichomes; type 2 to a narrow stripe of naked cuticle; type 3 to three rows of strong trichomes and six to seven rows of thin trichomes constitute type 4. While Wg, together with the Line protein (Hatini et al., 2000), is responsible for the formation of type 4 thin trichomes, different levels of $\mathrm{Hh}$ activity (Heemskerk and DiNardo, 1994) specify the formation of all other dorsal structures (Bokor and DiNardo, 1996; Hatini et al., 2000). At highest level, Hh determines the production of type 1 large hairs, intermediate levels give rise to naked cuticle and lower levels of Hh to type 3 trichomes (reviewed in (Hatini and DiNardo, 2001)).

In the ventral epidermis, the determination of epidermal cell identity involves additional signalling molecules that are expressed in adjacent stripes (Fig. 3B; see also Sanson, 2001 for review). The three anterior-most cell rows express Rhomboid, a trans-membrane protein required for the activation of Spitz (Lee et al., 2001), a ligand of the Drosophila EGF receptor (DER). Activation of the DER pathway determines the cell fate corresponding to anterior rows of denticles (O'Keefe et al., 1997; Szuts et al., 1997). Determination of the identity of posterior denticles rows requires the activity of Serrate (Alexandre et al., 1999; Wiellette and McGinnis, 1999), a ligand of the Notch pathway. wgexpression is maintained in the posterior-most cell row of the anterior compartment (van den Heuvel et al., 1989), while hhand engrailedare coexpressed in the two-cell wide posterior compartment. Results from genetic analyses indicate that the establishment and/or maintenance, of adjacent domains of signalling molecules involves cross regulation (Sanson, 2001). For example, restriction of serrate expression is thought to result from anterior repression by $\mathrm{Hh}$ and posterior repression by Wg (Alexandre et al., 1999; Wiellette and McGinnis, 1999).

\section{Morphogenesis of epidermal cells}

At mid-embryogenesis, epidermal cells undertake a reorganisation of their apical cytoskeleton. While F-actin is mainly cortical in cells that correspond to naked cuticle, cells that will form a trichome start to accumulate actin filaments in a focus, at the apex (Fig. 4A; see also Dickinson and Thatcher, 1997). These microfilaments are then bundled in an apical cone that grows perpendicular to the cell surface and will ultimately support the epidermal extension (Dickinson and Thatcher, 1997). Since the apical cell face of epidermal cells behaves as an internal mould for cuticle, formation of either naked cuticle or trichomes thus results from the control of apical cell shape that occurs during epidermal morphogenesis. In the ventral epidermis, $\mathrm{Wg}$ specifies the formation of naked cuticle. Embryos lacking wingless activity display a continuous lawn of denticles (Baker, 1987; Bejsovec and Martinez Arias, 1991), while ectopic expression of $\mathrm{Wg}$ throughout the epidermis gives rise to a naked ventral surface (Noordermeer et al., 1992). How does the Wingless signal instruct cells to make naked cuticle? While several members of the $\mathrm{Wg}$ pathway ( $\beta$-Catenin or Armadillo in Drosophila, Adenomatous Polyposis Coli) are in close contact with the cytoskeleton (McCartney et al., 1999), the essential activity of Wg in the determination of naked cuticle require a nuclear step that modifies transcription in naked cells (Payre
Fig. 3. Pattern of larval cuticular extensions. (A) The drawing schematises the organisation of cuticular extensions which decorate the external morphology of a young (first instar) Drosophila larva seen laterally (anterior is to the left and ventral to the bottom). (B) Detail of the dorsal and ventral cuticle corresponding to the fourth abdominal segment (A4). The dorsal region differentiates four kinds (1-4) of cuticle. The activity of the Hedgehog morphogen (yellow) specifies types 1 to 3, while Wingless (brown) determines the formation of thin trichomes (type 4). In the ventral side, members of several signalling pathways, which are expressed in a striped pattern in underlying epidermal cells, determine the formation of naked cuticle (Wingless) and the different kinds of ventral denticles. 
et al., 1999). Wnt signalling cascades are divided in canonical (mediated by $\beta$-catenin) and non-canonical pathways ( $\beta$-catenin independent) (Wodarz and Nusse, 1998). In canonical pathways, reception of the signal results in stabilisation of $\beta$-catenin, which can enter the nucleus and forms a multipartite transcription factor with TCF that regulate the expression of target genes (Wodarz and Nusse, 1998). The function of $\mathrm{Wg}$ in specifying naked cells is mediated by $\beta$-catenin (Armadillo) (Noordermeer et al., 1994) and embryos mutants for pangolin (the Drosophila TCF, or dTCF) (van de Wetering et al., 1997) develop a cuticle that looks like those resulting from a late $w g$ inactivation (Brunner et al., 1997). Altogether these data indicate that Wg signalling requires a transcriptional step to specify naked cuticle.

A determinant output of $\mathrm{Wg}$ signalling required for naked cuticle was shown to be the repression of shavenbabyexpression (Payre et al., 1999). shavenbaby (or shaven-baby, svb) is specifically expressed in any epidermal cell that will later form an extension (Fig. 4A; see also Mevel-Ninio et al., 1995; Payre et al., 1999). svb mutant embryos display essentially naked cuticle, albeit without recognisable segmentation defects (Fig. 4B). Furthermore, ectopic svbexpression is sufficient to force epidermal cells that would normally form naked cells to produce extensions (Fig. 4C; see also Payre et al., 1999; Delon et al., 2003). Therefore, svbexpression and activity is both required and sufficient to make an epidermal extension. Consistent with this conclusion, the activity of the DER pathway that promotes denticle formation is indeed mediated by activation of svbexpression (Payre etal., 1999). That shavenbaby is a critical player in the definition of the larval trichome pattern has recently received further support from the analysis of the mechanisms involved in the evolutionary diversification of the external larval morphology among dipteran. In several independent fly lineages, subsets of dorsal larval hairs are replaced by naked cuticle (Dickinson et al., 1993). Contrasting with the large number of molecules that are involved in the establishment of the trichome pattern during development, all examined cases of naked dorsal morphology in different fly species correlate with the modification of svb expression (Sucena and Stern, 2000; Khila et al., 2003; Sucena et al., 2003). In each case of trichome loss, while all other patterning genes that have been analysed display expression profiles indistinguishable from those of "hairy" species, svbexpression is restricted to the remaining epidermal cells that produce extensions in "naked" species (Sucena and Stern, 2000; Khila et al., 2003; Sucena et al., 2003). This shows that modification of svb epidermal expression has been repeatedly selected during evolution to generate novel trichome patterns. In addition, accumulated data from interspecific genetic analyses strongly support that it is the evolution of $s v b$ cis-control regions (Sucena and Stern, 2000; Sucena et al., 2003), rather than trans-regulatory factors, that has been responsible for this morphological diversification (reviewed in (Delon and Payre, 2004)).

Results emanating from both evolutionary and developmental studies therefore converge towards the importance of the control of $s v b$ expression in specifying the pattern of epidermal extensions. Svb encodes a large nuclear protein, including a DNA binding domain composed of 4 Cys2/His2 zinc fingers (Mevel-Ninio et al., 1995), that behaves as a transcription regulator (Andrews et al., 2000; Delon et al., 2003). The activity of svbon the expression of the Drosophilagenome is intimately involved in the reorganisation of components of the actin cytoskeleton (Delon et al., 2003). The

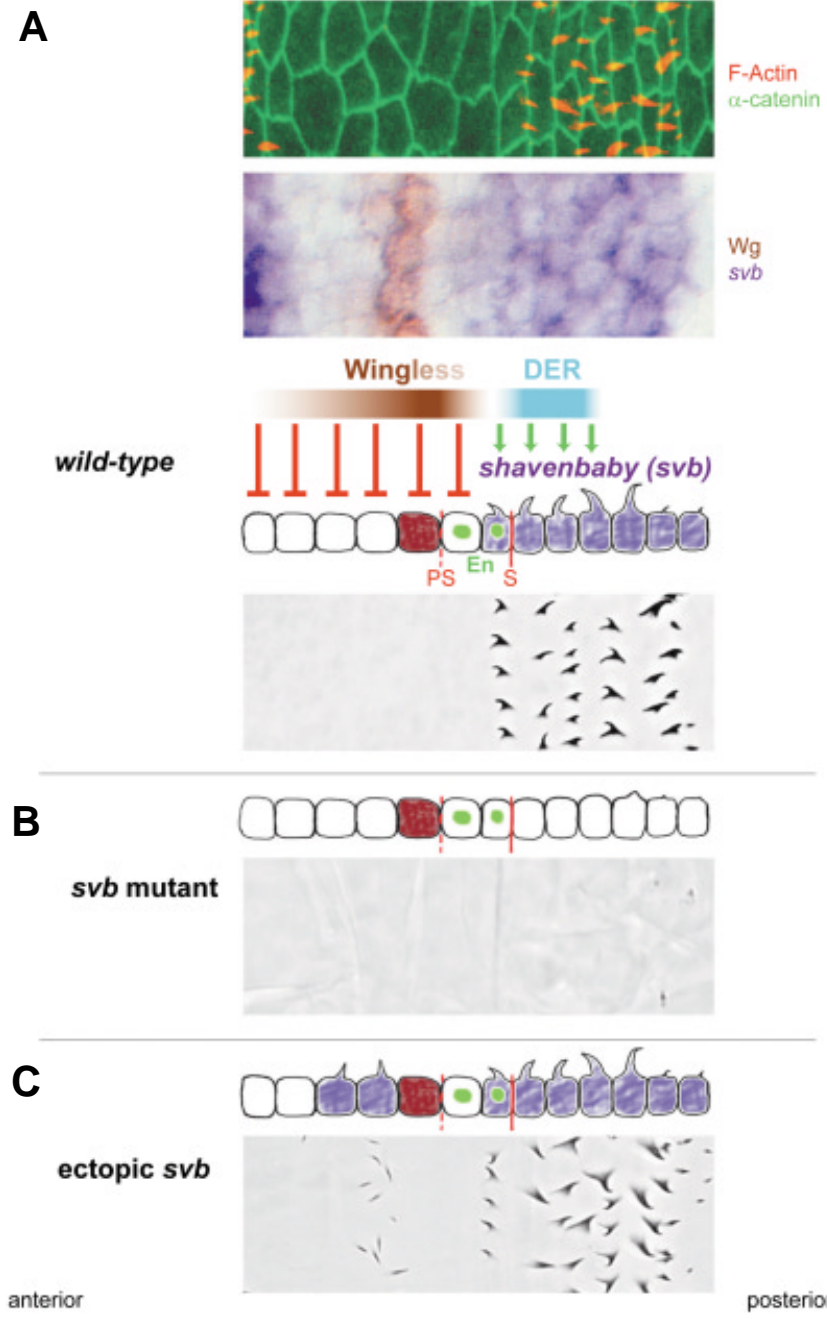

Fig. 4. Shavenbaby determines the pattern of larval extensions. In late wildtype embryos (A), epidermal cells display a reorganisation of the apical actin cytoskeleton which is responsible for the formation of extensions. The transcription of the shavenbaby (svb) gene (purple) integrates the antagonistic activities of the Wingless (brown) and DER (blue) signalling pathways, which respectively represses and activates svb expression, to define the pattern of epidermal extensions. While in svb mutant embryos (B) most of the cells are unable to produce extensions and differentiate naked cuticle, the ectopic expression of svb (C) is sufficient to force cells, which would otherwise make naked cuticle, to trigger the formation of extensions.

simplest model of Svb activity thus predict that this transcription factor activates the expression of genes encoding cytoskeletal components or regulators of cytoskeletal dynamics (Delon and Payre, 2004). Testing this prediction now awaits the identification of Svbtarget genes.

\section{Basic structure of the larval cuticle}

Before the completion of their morphogenesis, epidermal cells start secreting cuticle at their apical face. The cuticle is a characteristic of arthropod species that has certainly greatly contributed to their evolutive success. Most of our knowledge on cuticle is 
based on pioneering work of Vincent Wigglesworth (Lawrence and Locke, 1997) and Michael Locke. Its chemical nature remains unclear, but known aspects appear conserved among insects, for example between Drosophila and Rhodnius prolixus (see Locke, 2001 for review). Cuticle comprises hundred of proteins (Roter et al., 1985; Andersen et al., 1995), chitin (a polysaccharide composed essentially of $\mathrm{N}$-acetylglucosamine) and lipids. Modification of the protein matrix by quinone compounds (sclerotization) determines cuticle pigmentation (Riddiford and Hiruma, 1988 ) and rigidity, while local protein composition (Gosline et al., 2002) also influences its mechanical properties (e.g. Resilin is know to promote cuticle flexibility in various insects; Sannasi, 1970; Kannupandi, 1976; Haas et al., 2000). Enzymes responsible for catecholamine synthesis from tyrosine produce both $\mathrm{N}$-acetyldopamine and $\mathrm{N}$ - $\beta$-alanyldopamine (Sugumaran et al., 1992), which are oxidised to quinones by phenoloxydases. These compounds make covalent links between with proteins resulting in coloured products, a process called quinone tanning. Accordingly, mutations in several genes encoding enzymes of the catecholamine pathways, such as dopadecarboxyales ( $D d c$, amd), tyrosine hydroxylase (pale) and to a lesser extent yellow, lead to unpigmented larval cuticle (Martinez Arias, 1993). In addition, quinones may also form unstable methide derivatives that crosslink cuticle proteins through the quinone side chain (Saul and Sugumaran, 1988). This reaction, known as $\beta$-sclerotization, involves dibasic residues, such as histidine (Xu et al., 1996) and is primarily responsible for cuticle hardening. Ultrastructural studies have revealed that cuticle is formed of superposed layers. The procuticle, the thicker part of cuticle, lies directly on the epidermis and displays several lamellae, composed of proteins and polarised chitin microfibrils (Neville et al., 1976). The outermost layer of cuticle is referred to as the epicuticle, which primary function is to reduce water loss (Wigglesworth, 1985) and protect the insect from abrasion. Epicuticle is mainly composed of lipoproteins, fatty acids and polyphenols. Again, several layers of epicuticle can be distinguished. The inner protein epicuticle is the thickest layer and is located just above the procuticle. The thin outer epicuticle, or cuticulin, appears as an external membrane (Locke, 1966), that may be covered by wax and cement layers. Only a small number of cuticle components are currently known and identification of other molecules will be critical to understand cuticle formation and functional organisation.

\section{The insect epidermis as a secreting organ}

Whenever epidermal cells secrete cuticle, their apical face present an organised array of microvilli, which are supported by parallel actin filaments orientated along the basal-apical axis (Fig. 5; see also Locke, 2001). While cuticulin forma- tion is restricted to the tip of microvilli early, it eventually extends to form a continuous envelope (Locke, 2001). Epicuticle then forms, through secretory vesicles that discharge their content in the intermicrovillar space (Locke, 2001). Mutations inactivating Sec61 $\beta$, a component of the protein-conducting channel of the endoplasmic reticulum, result in gross abnormality in cuticle deposition, with no sign of epicuticle formation (Valcarcel et al., 1999). In the same vein, Syntaxin1A, a protein involved in the fusion of synaptic vesicles with their target membrane, is also required for cuticle formation (Schulze and Bellen, 1996). This shows that active and highly regulated exocytosis is critical for cuticle deposition. Coated vesicles, which present the characteristic of endocytosis particles, are also observed at the apical face of epidermal cells, suggesting that the composition of cuticular compartment is dynamically controlled during cuticle deposition (Locke, 2001). The successive layers of chitin-containing lamellae are subsequently secreted and deposed in an assembly zone that lies on the tip of microvilli (Locke, 2001). After cellulose, chitin is the most abundant polysaccharide in living organisms. Its massive synthesis requires high amounts of monomer and the basal region of Drosophila epidermal cells is filled with glycogen reserves. Mutations in krotzkopf verkehrt( kkv), the gene encoding Drosophila chitin synthase (Ostrowski et al., 2002), or inhibition of chitin synthesis with luferunon treatment, both provoke a characteristic phenotype, called the "blimp" phenotype. Mutant embryos for $k k v$ are unable to hatch and display poor cuticle integrity when mechanically removed from the egg envelopes (Ostrowski et al., 2002). In addition, kkvembryos show excessive cuticle stretching when compare to wild-type, indicating that the mutant cuticle is abnormally soft (Ostrowski et al., 2002). A similar phenotype results from the inactivation of grainy-head, a gene encoding a GATA transcription factor (Lee and Adler, 2004). Grainy-head regulates the expression of knickkopf, a gene, which encodes a novel protein involved in cuticle formation. grainy-head also activates the transcription of the gene encoding Dopa-decarboxylase, an enzyme that converts Dopa to Dopamine and thus required for $\beta$-sclerotization (Wright et al., 1976). Two other mutants known to affect cuticle formation, retroactive and zeppelin, remain to be mo-

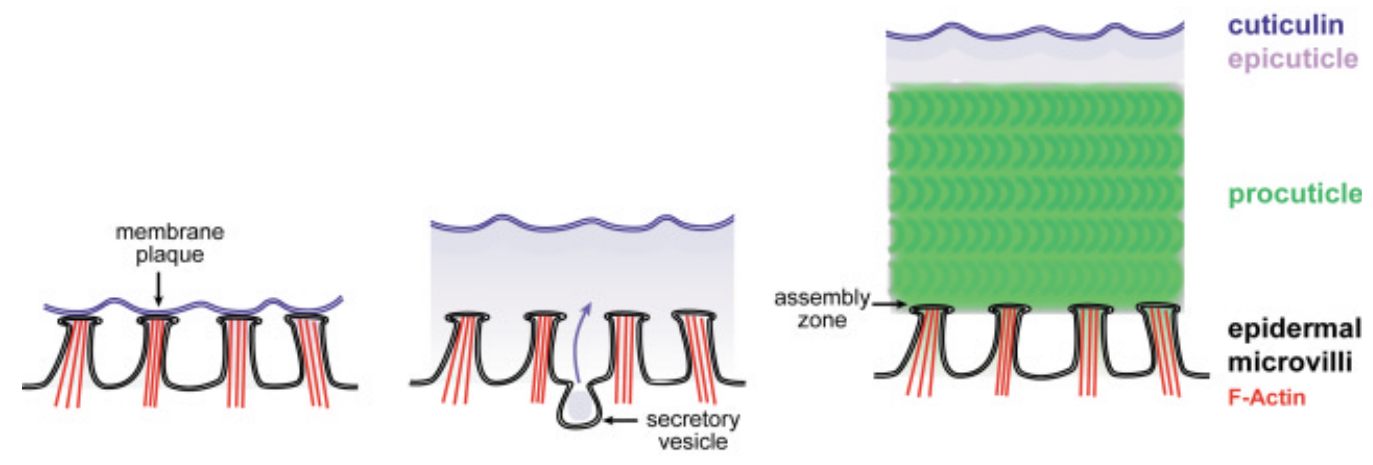

Fig. 5. Schematic representation of the formation of the different cuticle layers. The first cuticle layer that is laid corresponds to the outer-most envelope (or cuticulin, in blue). The cuticulin is deposed at the top of epidermal cell microvilli, at the so-called membrane plaques. A different cellular process, which involves the apical delivery of secretory vesicles, is responsible for the formation of the epicuticle (light blue) that is assembled at the inner face of the envelope. The thicker layer of cuticle is made of successive laminae of chitin microfibers (green), formed above microvilli in an assembly zone (adapted from (Locke, 2001)). 
lecularly characterised (Ostrowski et al., 2002). Finally, the fly genome contains a second predicted chitin synthase gene but the analysis of its putative function during cuticle formation awaits the isolation of mutations. Epidermal cells also display endocytosis at their basal face, e.g. for the import of tyrosine from the underlying haemolymph, which is not synthesised by insects (Locke, 2001). Finally, epidermal cells undergo transepithelial transport of molecules, which have been shown to be of critical importance for diffusion of morphogenic signals such as Wingless (Dubois et al., 2001). Altogether, these data highlight that the mono-layered Drosophila embryonic epidermis is actually a very active secretory organ, whose function involves a precisely choreographed ballet of vesicles that remains largely unexplore. In addition, the cuticle has to be shed and replaced at each molt to allow larval growth. Thus, the cuticle can be viewed as a living cellular compartment that is continuously modified during development.

\section{Concluding remarks}

For more than a century, work using Drosophila continue to enrich our understanding of biological processes. These studies have largely contributed to the establishment of founding concepts, such as the physical nature of the genes or the genetic control of development. Drosophila has also provided the first detailed understanding of the molecular basis underlying embryonic segmentation. Although segmentation might (or not) correspond to an ancient feature (Kimmel, 1996) already present in the common ancestor of animal species with lateral symmetry, the Urbilateria (De Robertis and Sasai, 1996), numerous data indicate that flies exhibit an evolutionarily derived mode of segmentation that is not related to that of vertebrates (Patel, 2003; Peel and Akam, 2003). By contrast and despite the numerous differences in morphology and organisation observed between the epidermis of Drosophila and vertebrates, the genetic cascades that control epidermis differentiation appear to have been evolutionary conserved. Interestingly, all the signalling pathways (Wnt, Hh, EGF-R, Notch) that determine Drosophila epidermal morphogenesis are also involved at different level of epidermal differentiation in vertebrates. In addition, the analysis of Drosophila epidermis has revealed an unsuspected level of similarity between fly and mammalian epithelial cells in regards to the molecular mechanisms governing the establishment of cellular junctions and polarity. Therefore, the simple organisation of the Drosophila epidermis, allied to the power of genetic approaches in flies, constitute a major asset for learning about epidermal morphogenesis and provides information relevant for other species. Understanding Drosophila epidermal morphogenesis will require bringing together developmental genetics and cellular biology. Most developmental process are not currently analysed in enough (cellular and subcellular) details, whereas the environment of a cell in a living organism cannot be mimicked in plastic dishes, even upon the addition of undefined "matrix". While recent developments of in vivo imaging techniques certainly bring invaluable help, we should not forget older knowledge and technology. Most of what we have learned about cuticle structure in Drosophila comes from early observations made with the electron microscope and ultrastructural studies are certainly of promise for the future, since they are indispensable for understanding what is taking place "inside" the cell. As living products of evolution, we have to remember that new avenues are always paved with used materials.

\section{Acknowledgements}

I thank very much P. Blader, F. Roch, L. Védé, I. Delon, H. ChanutDelalande, $S$. Plaza and other members of the lab for critical reading of the manuscript and helpfuldiscussions. This work was supported by grants from Association pour la Recherche contre le Cancer (ARC $n^{\circ}$ 5116) and from the Ministère de la Jeunesse Education Nationale et de la Recherche (ACl Biologie du Développement et Physiologie Intégrative, ref. 030023).

\section{References}

ALEXANDRE, C., LECOURTOIS, M. and VINCENT, J. P. (1999). Wingless and Hedgehog pattern Drosophila denticle belts by regulating the production of shortrange signals. Development 126: 5689-98.

ANDERSEN, S. O., HOJRUP, P. and ROEPSTORFF, P. (1995). Insect cuticular proteins. Insect Biochem. Mol. Biol. 25: 153-76.

ANDREWS, J., GARCIA-ESTEFANIA, D., DELON, I., LU, J., MEVEL-NINIO, M., SPIERER, A., PAYRE, F., PAULI, D. and OLIVER, B. (2000). OVO transcription factors function antagonistically in the Drosophilafemale germline. Development 127: 881-92.

BAKER, N. E. (1987). Molecular cloning of sequences from wingless, a segment polarity gene in Drosophila: the spatial distribution of a transcript in embryos. EMBO J. 6: 1765-1773.

BAUMGARTNER, S., LITTLETON, J. T., BROADIE, K., BHAT, M. A., HARBECKE, R., LENGYEL, J. A., CHIQUET-EHRISMANN, R., PROKOP, A. and BELLEN, H. J. (1996). A Drosophilaneurexin is required for septate junction and blood-nerve barrier formation and function. Cel/87: 1059-68.

BEJSOVEC, A. and MARTINEZ ARIAS, A. (1991). Roles of winglessin patterning the larval epidermis of Drosophila. Development 113: 471-85.

BENTON, R. and ST JOHNSTON, D. (2003). A conserved oligomerization domain in Drosophila Bazooka/PAR-3 is important for apical localization and epithelial polarity. Curr. Biol. 13: 1330-4.

BERONJA, S. and TEPASS, U. (2002). Cellular morphogenesis: slow-as-molasses accelerates polarized membrane growth. Dev. Cel/2: 382-4.

BILDER, D., SCHOBER, M. and PERRIMON, N. (2003). Integrated activity of PDZ protein complexes regulates epithelial polarity. Nat. Cell. Biol. 5: 53-8.

BOKOR, P. and DINARDO, S. (1996). The roles of hedgehog, wingless and lines in patterning the dorsal epidermis in Drosophila. Development 122: 1083-92.

BRUNNER, E., PETER, O., SCHWEIZER, L. and BASLER, K. (1997). pangolin encodes a Lef- 1 homologue that acts downstream of armadillo to transduce the Wingless signal in Drosophila. Nature 385: 829-33.

COHEN, B. (1995). Nobel committee rewards pioneers of development studies in fruitflies. Nature 377: 465.

DE ROBERTIS, E. M. and SASAI, Y. (1996). A common plan for dorsoventral patterning in Bilateria. Nature 380: $37-40$.

DELON, I., CHANUT-DELALANDE, H. and PAYRE, F. (2003). The Ovo/Shavenbaby transcription factor specifies actin remodelling during epidermal differentiation in Drosophila. Mech. Dev. 120: 747-58.

DELON, I. and PAYRE, F. (2004). Evolution of larval morphology in flies: get in shape with shavenbaby. Trends Genet: in press.

DICKINSON, W. J., TANG, Y., SCHUSKE, K. and AKAM, M. (1993). Conservation of molecular prepatterns during the evolution of cuticle morphology in Drosophila larvae. Evolution 47: 1396-1406.

DICKINSON, W. J. and THATCHER, J. W. (1997). Morphogenesis of denticles and hairs in Drosophila embryos: involvement of actin-associated proteins that also affect adult structures. Cell Motil. Cytoskeleton 38: 9-21.

DUBOIS, L., LECOURTOIS, M., ALEXANDRE, C., HIRST, E. and VINCENT, J. P. (2001). Regulated endocytic routing modulates wingless signaling in Drosophila embryos. Cel/105: 613-24. 
FOE, V. E. (1989). Mitotic domains reveal early commitment of cells in Drosophila embryos. Development 107: 1-22.

GLISE, B., BOURBON, H. and NOSELLI, S. (1995). hemipterous encodes a novel DrosophilaMAP kinase kinase, required for epithelial cell sheet movement. Cel/83: 451-61.

GLISE, B. and NOSELLI, S. (1997). Coupling of Jun amino-terminal kinase and Decapentaplegic signaling pathways in Drosophila morphogenesis. Genes Dev. 11: 1738-47.

GOSLINE, J., LILLIE, M., CARRINGTON, E., GUERETTE, P., ORTLEPP, C. and SAVAGE, K. (2002). Elastic proteins: biological roles and mechanical properties. Philos. Trans R. Soc. Lond. B. Biol. Sci. 357: 121-32.

HAAS, F., GORB, S. and BLICKHAN, R. (2000). The function of resilin in beetle wings. Proc. R. Soc. Lond. B. Biol. Sci. 267: 1375-81.

HATINI, V., BOKOR, P., GOTO-MANDEVILLE, R. and DINARDO, S. (2000). Tissueand stage-specific modulation of Wingless signaling by the segment polarity gene lines. Genes Dev. 14: 1364-76.

HATINI, V. and DINARDO, S. (2001). Divide and conquer: pattern formation in Drosophila embryonic epidermis. Trends Genet. 17: 574-9.

HEEMSKERK, J. and DINARDO, S. (1994). DrosophilaHedgehog acts as a morphogen in cellular patterning. Cel/76: 449-60.

HOU, X. S., GOLDSTEIN, E. S. and PERRIMON, N. (1997). Drosophila Jun relays the Jun amino-terminal kinase signal transduction pathway to the Decapentaplegic signal transduction pathway in regulating epithelial cell sheet movement. Genes Dev. 11: 1728-37

HURD, T. W., GAO, L., ROH, M. H., MACARA, I. G. and MARGOLIS, B. (2003). Direct interaction of two polarity complexes implicated in epithelial tight junction assembly. Nat. Cell. Biol. 5: 137-42.

INGHAM, P. W. (1993). Localized hedgehog activity controls spatial limits of wingless transcription in the Drosophila embryo. Nature 366: 560-2.

INGHAM, P. W. and MCMAHON, A. P. (2001). Hedgehog signaling in animal development: paradigms and principles. Genes Dev. 15: 3059-3087.

JACINTO, A., WOOD, W., BALAYO, T., TURMAINE, M., MARTINEZ-ARIAS, A. and MARTIN, P. (2000). Dynamic actin-based epithelial adhesion and cell matching during Drosophila dorsal closure. Curr. Biol. 10: 1420-6.

JACINTO, A., WOOD, W., WOOLNER, S., HILEY, C., TURNER, L., WILSON, C., MARTINEZ-ARIAS, A. and MARTIN, P. (2002a). Dynamic analysis of actin cable function during Drosophila dorsal closure. Curr. Biol. 12: 1245-50.

JACINTO, A., WOOLNER, S. and MARTIN, P. (2002b). Dynamic analysis of dorsal closure in Drosophila: from genetics to cell biology. Dev. Cel/3: 9-19.

KANNUPANDI, T. (1976). Occurrence of resilin and its significance in the cuticle of Pennella elegans, a copepod parasite. Acta Histochem. 56: 73-9.

KHILA, A., EL HAIDANI, A., VINCENT, A., PAYRE, F. and SOUDA, S. I. (2003). The dual function of ovo/shavenbaby in germline and epidermis differentiation is conserved between Drosophila melanogaster and the olive fruit fly Bactrocera oleae. Insect Biochem. Mol. Biol. 33: 691-9.

KIEHART, D. P., GALBRAITH, C. G., EDWARDS, K. A., RICKOLL, W. L. and MONTAGUE, R. A. (2000). Multiple forces contribute to cell sheet morphogenesis for dorsal closure in Drosophila. J. Cell. Biol. 149: 471-90.

KIMMEL, C. B. (1996). Was Urbilateria segmented? Trends Genet. 12: 329-31.

KNUST, E. (1997). Drosophilamorphogenesis: movements behind the edge. Curr. Biol. 7: R558-61.

KNUST, E. and BOSSINGER, O. (2002). Composition and formation of intercellular junctions in epithelial cells. Science 298: 1955-9.

KORNEZOS, A. and CHIA, W. (1992). Apical secretion and association of the Drosophila yellow gene product with developing larval cuticle structures during embryogenesis. Mol. Gen. Genet. 235: 397-405.

LAMB, R. S., WARD, R. E., SCHWEIZER, L. and FEHON, R. G. (1998). Drosophila Coracle, a member of the protein 4.1 superfamily, has essential structural functions in the septate junctions and developmental functions in embryonic and adult epithelial cells. Mol. Biol. Cell. 9: 3505-19.

LARSEN, C. W., HIRST, E., ALEXANDRE, C. and VINCENT, J. P. (2003). Segment boundary formation in Drosophila embryos. Development 130: 5625-35.

LAWRENCE, P. A. and LOCKE, M. (1997). A man for our season. Nature 386: 757-8. LECUIT, T., SAMANTA, R. and WIESCHAUS, E. (2002). slam encodes a develop- mental regulator of polarized membrane growth during cleavage of the Drosophila embryo. Dev. Cel/2: 425-36.

LECUIT, T. and WIESCHAUS, E. (2000). Polarized insertion of new membrane from a cytoplasmic reservoir during cleavage of the Drosophila embryo. J. Cell. Biol. 150: 849-60.

LECUIT, T. and WIESCHAUS, E. (2002). Junctions as organizing centers in epithelial cells? A fly perspective. Traffic $3:$ 92-7.

LEE, H. and ADLER, P. N. (2004). The Grainy head transcription factor is essential for the function of the frizzled pathway in the Drosophila wing. Mech. Dev. 121:37-49.

LEE, J. R., URBAN, S., GARVEY, C. F. and FREEMAN, M. (2001). Regulated intracellular ligand transport and proteolysis control EGF signal activation in Drosophila. Cel/107: 161-71.

LOCKE, M. (1966). The structure and formation of the cuticulin layer in the epicuticle of an insect, Calpodes ethlius (Lepidoptera, Hesperiidae). J. Morphol. 118: 46194.

LOCKE, M. (2001). The Wigglesworth Lecture: Insects for studying fundamental problems in biology. J. Insect Physiol. 47: 495-507.

LONCAR, D. and SINGER, S. J. (1995). Cell membrane formation during the cellularization of the syncytial blastoderm of Drosophila. Proc. Natl. Acad. Sci. USA 92: 2199-203.

MARTINEZ ARIAS, A. (1993). Development and patterning of the larval epidermis of Drosophila. Pages 517-608 in M. BATE and A. MARTINEZ ARIAS, eds. The development of Drosophila melanogaster. Cold Spring Harbor Laboratory Press, Cold Spring Harbor.

MCCARTNEY, B. M., DIERICK, H. A., KIRKPATRICK, C., MOLINE, M. M., BAAS, A. PEIFER, M. and BEJSOVEC, A. (1999). Drosophila APC2 is a cytoskeletallyassociated protein that regulates wingless signaling in the embryonic epidermis. J. Cell. Biol. 146: 1303-18.

MEDINA, E., WILLIAMS, J., KLIPFELL, E., ZARNESCU, D., THOMAS, G. and LE BIVIC, A. (2002). Crumbs interacts with moesin and beta(Heavy)-spectrin in the apical membrane skeleton of Drosophila. J. Cell. Biol. 158: 941-51.

MEVEL-NINIO, M., TERRACOL, R., SALLES, C., VINCENT, A. and PAYRE, F. (1995). ovo, a Drosophila gene required for ovarian development, is specifically expressed in the germline and shares most of its coding sequences with shavenbaby, a gene involved in embryo patterning. Mech. Dev. 49: 83-95.

MULLER, H. A. (2000). Genetic control of epithelial cell polarity: lessons from Drosophila. Dev. Dyn. 218: 52-67.

MULLER, H. A. and WIESCHAUS, E. (1996). armadillo, bazooka and stardustare critical for early stages in formation of the zonula adherensand maintenance of the polarized blastoderm epithelium in Drosophila. J. Cell. Biol. 134: 149-63.

NEVILLE, A. C., PARRY, D. A. and WOODHEAD-GALLOWAY, J. (1976). The chitin crystallite in arthropod cuticle. J. Cell Sci. 21: 73-82.

NOORDERMEER, J., JOHNSTON, P., RIJSEWIJK, F., NUSSE, R. and LAWRENCE, P. A. (1992). The consequences of ubiquitous expression of the wingless gene in the Drosophila embryo. Development 116: 711-9.

NOORDERMEER, J., KLINGENSMITH, J., PERRIMON, N. and NUSSE, R. (1994). dishevelled and armadillo act in the wingless signalling pathway in Drosophila. Nature 367: 80-3.

NOSELLI, S. and AGNES, F. (1999). Roles of the JNK signaling pathway in Drosophila morphogenesis. Curr. Opin. Genet. Dev. 9: 466-72.

NUSSLEIN-VOLHARD, C. and WIESCHAUS, E. (1980). Mutations affecting segmen number and polarity in Drosophila. Nature 287: 795-801.

NUSSLEIN-VOLHARD, C., WIESCHAUS, E. and KLUDING, H. (1984). Mutations affecting the pattern of the larval cuticle in Drosophila melanogaster. Roux Arch. Dev. Biol. 193: 267-282.

O'KEEFE, L., DOUGAN, S. T., GABAY, L., RAZ, E., SHILO, B. Z. and DINARDO, S. (1997). Spitz and Wingless, emanating from distinct borders, cooperate to establish cell fate across the Engrailed domain in the Drosophila epidermis. Development 124: 4837-45.

OSTROWSKI, S., DIERICK, H. A. and BEJSOVEC, A. (2002). Genetic control of cuticle formation during embryonic development of Drosophila melanogaster. Genetics 161: 171-82

PANKRATZ, J. and JÄCKLE, H. (1993). Blastoderm Segmentation. Pages 467-516 in M. BATE and A. MARTINEZ ARIAS, eds. The development of Drosophila melanogaster. Cold Spring Harbor Laboratory Press, Cold Spring Harbor. 
PATEL, N. H. (2003). The ancestry of segmentation. Dev. Cel/5: 2-4.

PAYRE, F., VINCENT, A. and CARRENO, S. (1999). ovo/svbintegrates Wingless and DER pathways to control epidermis differentiation. Nature 400: 271-5.

PAZDERA, T. M., JANARDHAN, P. and MINDEN, J. S. (1998). Patterned epidermal cell death in wild-type and segment polarity mutant Drosophila embryos. Development 125: 3427-36.

PEEL, A. and AKAM, M. (2003). Evolution of segmentation: rolling back the clock. Curr. Biol. 13: R708-10.

POLESELLO, C. and PAYRE, F. (2004). Small is beautiful: what flies tell us about ERM function in development. Trends Cel/ Biol: in press.

RIDDIFORD, L. M. and HIRUMA, K. (1988). Regulation of melanization in insect cuticle. Prog. Clin. Biol. Res. 256: 423-36.

ROLLS, M. M., ALBERTSON, R., SHIH, H. P., LEE, C. Y. and DOE, C. Q. (2003). DrosophilaaPKC regulates cell polarity and cell proliferation in neuroblasts and epithelia. J. Cell. Biol. 163: 1089-98.

ROTER, A. H., SPOFFORD, J. B. and SWIFT, H. (1985). Synthesis of the major adult cuticle proteins of Drosophila melanogasterduring hypoderm differentiation. Dev. Biol. 107: 420-31.

SANNASI, A. (1970). Resilin in the lens cuticle of the firefly, Photinus pyralis Linnaeus. Experientia 26: 154.

SANSON, B. (2001). Generating patterns from fields of cells. Examples from Drosophila segmentation. EMBO Rep. 2: 1083-8.

SAUL, S. and SUGUMARAN, M. (1988). A novel quinone: quinone methide isomerase generates quinone methides in insect cuticle. FEBS Lett. 237: 1558.

SCHEJTER, E. D. and WIESCHAUS, E. (1993). bottleneck acts as a regulator of the microfilament network governing cellularization of the Drosophila embryo. Cel/75: 373-85.

SCHONBAUM, C. P., ORGAN, E. L., QU, S. and CAVENER, D. R. (1992). The Drosophila melanogaster stranded at second (sas) gene encodes a putative epidermal cell surface receptor required for larval development. Dev. Biol. 151: 431-45.

SCHULZE, K. L. and BELLEN, H. J. (1996). Drosophila syntaxinis required for cell viability and may function in membrane formation and stabilization. Genetics 144: 1713-24.

SCHWEISGUTH, F., LEPESANT, J. A. and VINCENT, A. (1990). The serendipity alpha gene encodes a membrane-associated protein required for the cellularization of the Drosophila embryo. Genes Dev. 4: 922-31.

SIMPSON, L. and WIESCHAUS, E. (1990). Zygotic activity of the nullo locus is required to stabilize the actin-myosin network during cellularization in Drosophila. Development 110: 851-63.

ST JOHNSTON, D. and NUSSLEIN-VOLHARD, C. (1992). The origin of pattern and polarity in the Drosophila embryo. Cel/68: 201-219.

SUCENA, E., DELON, I., JONES, I., PAYRE, F. and STERN, D. L. (2003). Regulatory evolution of shavenbaby/ovo underlies multiple cases of morphological parallelism. Nature 424: 935-8.

SUCENA, E. and STERN, D. L. (2000). Divergence of larval morphology between Drosophila sechellia and its sibling species caused by cis-regulatory evolution of ovolshaven-baby. Proc. Natl. Acad. Sci. USA 97: 4530-4.

SUGUMARAN, M., GIGLIO, L., KUNDZICZ, H., SAUL, S. and SEMENSI, V. (1992). Studies on the enzymes involved in puparial cuticle sclerotization in Drosophila melanogaster. Arch. Insect Biochem. Physiol. 19: 271-83.

SULLIVAN, W., FOGARTY, P. and THEURKAUF, W. (1993). Mutations affecting the cytoskeletal organization of syncytial Drosophila embryos. Development 118: $1245-54$.
SZUTS, D., FREEMAN, M. and BIENZ, M. (1997). Antagonism between EGFR and Wingless signalling in the larval cuticle of Drosophila. Development 124: 320919.

TEPASS, U. (1996). Crumbs, a component of the apical membrane, is required for zonula adherens formation in primary epithelia of Drosophila. Dev. Biol. 177: 217-25.

TEPASS, U., THERES, C. and KNUST, E. (1990). crumbs encodes an EGF-like protein expressed on apical membranes of Drosophila epithelial cells and required for organization of epithelia. Ce//61: 787-99.

THOMAS, J. H. and WIESCHAUS, E. (2004). src64 and tec29 are required for microfilament contraction during Drosophila cellularization. Development 131 863-71.

VALCARCEL, R., WEBER, U., JACKSON, D. B., BENES, V., ANSORGE, W., BOHMANN, D. and MLODZIK, M. (1999). Sec61beta, a subunit of the protein translocation channel, is required during Drosophila development. J. Cell Sci. 112 (Pt 23): 4389-96.

VAN DE WETERING, M., CAVALLO, R., DOOIJES, D., VAN BEEST, M., VAN ES, J., LOUREIRO, J., YPMA, A., HURSH, D., JONES, T., BEJSOVEC, A., PEIFER, M. MORTIN, M. and CLEVERS, H. (1997). Armadillo coactivates transcription driven by the product of the Drosophila segment polarity gene dTCF. Cel/88: 789-99.

VAN DEN HEUVEL, M., NUSSE, R., JOHNSTON, P. and LAWRENCE, P. A. (1989). Distribution of the wingless gene product in Drosophila embryos: a protein involved in cell-cell communication. Cel/59: 739-49.

WARN, R. M., BULLARD, B. and MAGRATH, R. (1980). Changes in the distribution of cortical myosin during the cellularization of the Drosophila embryo. J. Embryol. Exp. Morphol. 57: 167-76.

WARN, R. M. and ROBERT-NICOUD, M. (1990). F-actin organization during the cellularization of the Drosophila embryo as revealed with a confocal laser scanning microscope. J. Cel/ Sci. 96 (Pt 1): 35-42.

WIELLETTE, E. L. and MCGINNIS, W. (1999). Hox genes differentially regulate Serrate to generate segment-specific structures. Development 126: 1985-95.

WIESCHAUS, E. and SWEETON, D. (1988). Requirements for X-linked zygotic gene activity during cellularization of early Drosophilaembryos. Development 104: 48393.

WIGGLESWORTH, V. B. (1985). Sclerotin and lipid in the waterproofing of the insect cuticle. Tissue Cel/17: 227-48.

WODARZ, A. and NUSSE, R. (1998). Mechanisms of Wnt signaling in development. Annu. Rev. Cell. Dev. Biol. 14: 59-88.

WOOD, W., JACINTO, A., GROSE, R., WOOLNER, S., GALE, J., WILSON, C. and MARTIN, P. (2002). Wound healing recapitulates morphogenesis in Drosophila embryos. Nat. Cell. Biol. 4: 907-12.

WOODS, D. F., WU, J. W. and BRYANT, P. J. (1997). Localization of proteins to the apico-lateral junctions of Drosophila epithelia. Dev. Genet. 20: 111-8.

WRIGHT, T. R., BEWLEY, G. C. and SHERALD, A. F. (1976). The genetics of dopa decarboxylase in Drosophilamelanogaster. II. Isolation and characterization of dopa-decarboxylase-deficient mutants and their relationship to the alphamethyl-dopa-hypersensitive mutants. Genetics 84: 287-310.

XU, R., HUANG, X., MORGAN, T. D., PRAKASH, O., KRAMER, K. J. and HAWLEY M. D. (1996). Characterization of products from the reactions of $\mathrm{N}$-acetyldopamine quinone with N-acetylhistidine. Arch. Biochem. Biophys. 329: 56-64.

YOUNG, P. E., PESACRETA, T. C. and KIEHART, D. P. (1991). Dynamic changes in the distribution of cytoplasmic myosin during Drosophila embryogenesis. Development 111: 1-14.

YOUNG, P. E., RICHMAN, A. M., KETCHUM, A. S. and KIEHART, D. P. (1993). Morphogenesis in Drosophila requires nonmuscle myosin heavy chain function. Genes Dev. 7: 29-41. 